\title{
Intelectuais, conhecimento e espaço público
}

\author{
Francisco de Oliveira \\ Universidade de São Paulo, Faculdade de Filosofia, Letras e Ciências Humanas \\ Centro de Estudos dos Direitos da Cidadania
}

Conferência de abertura da $24^{a}$ Reunião Anual da ANPEd

É com enorme satisfação e ao mesmo tempo enorme responsabilidade que venho falar para este auditório formado pelos que lutam pela educação no Brasil. Meus parabéns a ANPEd pelos seus 25 anos! É uma senhora jovem ainda. Meus parabéns por essa festa, que é a $24^{\mathrm{a}}$ Reunião Anual da Associação.

Entre amigos se cometem sempre exageros. Portanto, um primeiro conselho, dado por um grande especialista na alma humana. Não vou citar nenhum dos nossos clássicos, mas Groucho Marx: "Duvidem do clube que os acolhe como sócios." Portanto, duvidem muito dos elogios entre amigos. Com isso quero dizer que me honra muito estar entre vocês e poder ajudar nesta luta travada cotidianamente. Eespero diminuir um pouco as expectativas a respeito desta conferência.

É extremamente difícil tratar o tema dessa relação que é reciprocamente fundadora: Intelectuais, $c o$ nhecimento e espaço público. Na verdade, eles nascem juntos. O intelectual moderno constrói-se naquele momento em que Weber chamou de desencantamento do mundo, desligado dos mecanismos tradicionais da dominação e do poder, sobretudo da Igreja e do Estado. Não é mais uma extensão da Igreja, nem do Esta- do. Ergue-se exatamente nessa transição e com ele surgem, ao mesmo tempo, não se podendo dizer quem veio primeiro, a tarefa do intelectual e o seu campo de atuação: o campo do conhecimento. Tudo isso ocorre mediante uma operação em que se desprivatiza o espaço. O espaço passa a ser um lugar público, lugar eficaz para a operação do novo modo de ser da sociedade. O intelectual é, portanto, este agente que, neste momento, descola-se dos antigos aparelhos e das antigas formas de dominação, e surge autônomo. Não importa se na história mais concreta muitos intelectuais estiveram a serviço do poder; tomemos o mais emblemático deles, talvez o fundador do intelectual moderno: Maquiavel, conhecido por sua obra clássica, $O$ Príncipe. Esta parece ser uma obra destinada a dar conselhos aos príncipes. Tratar-se-ia, portanto, de alguém que nega, exatamente no momento de sua criação, o espaço público e sua independência. Mas, para os que conhecem melhor a obra, o conselho de Maquiavel é para a República. Ele afirma, pois, o espaço público.

Este é o momento fundador desta relação profícua. Seria tolice dizer que os séculos anteriores foram 
marcados pela ignorância, obscurantismo e falta de conhecimento. O que se deve assinalar é essa junção em que os três elementos se constituem simultaneamente e se reforçam. O conhecimento foi produzido muito antes, mas sempre na dependência do poder, em instituições cujos objetivos eram evitar a publicização. A história é rica de pensadores; mas, salvo talvez na Grécia Clássica, eles se constituíam sempre em apêndices, da Igreja ou do Estado. Esse momento fundador coincide com a abertura do Novo Mundo, marcando precisamente o nascimento desta relação entre Intelectual, conhecimento e espaço público. O intelectual passará a ser um produtor de conhecimento independente: a finalidade da produção do conhecimento é conhecer.

Parece uma simples tautologia, mas significa uma revolução profunda nas formas mediante as quais o conhecimento se colocava a serviço dos mecanismos de dominação. Sabemos também, como assinalaria séculos depois Foucault, que daí vai nascer também um novo tipo de poder: um poder fundado precisamente no saber, apoiado, ancorado numa relação com os novos saberes que instalam e instauram novas práticas. Mas não devemos ser ingênuos e nem pensar que a aventura do conhecimento é pura liberdade; ela trabalha sempre em uma tensão dialética entre liberdade e dominação. Vai surgir, portanto, a virtualidade de que esses novos saberes instaurem novos poderes, novas práticas de dominação.

Desse ponto de vista, a educação tem que estar atenta a essa ambigüidade, e inscrita no momento mesmo de sua gênesis. Ela não lhe é estranha, nem é algo que lhe foi anexado ou deturpado, nem é um desvio; é uma espécie de nascimento congênito. A virtualidade abre-se para que as novas práticas, que constituem novos saberes, determinem e possam fazer nascer novos modos de dominação. Essa é uma vertente muito conhecida hoje, graças aos trabalhos de Foucault: de como, a partir desse momento, se instaurou uma nova relação. Como sabemos, esse caminhar do conhecimento dos intelectuais e do espaço público levou às especializações. As especializações que hoje, depois de revisões intensas e profundas, são postas em questão, em seu primeiro momento representaram uma es- pécie de radicalização do desencantamento do mundo. É como se buscássemos desesperadamente tornar tudo transparente à razão. A razão devia ser um instrumento pelo qual e através do qual, sem nenhuma dissociação, a humanidade fosse capaz de tornar transparente e conhecer com precisão toda a ordem de fenômenos, desde os naturais, os cosmológicos, até os mais íntimos do Homem, da Humanidade. Portanto, essas especializações são uma espécie de reafirmação do desencantamento; uma tentativa de se chegar às raízes últimas ou às raízes primeiras de todos os fenômenos. Começando pelos fenômenos da natureza e terminando no século XIX e já avançando no século XX, tentase investigar aquilo que se passa na constituição das próprias sociedades. Mais adiante, agora com Freud, tenta-se, se não curar, pelo menos indagar e especular sobre o que se passa no mais íntimo das pessoas, naquele território do qual elas mesmas são inconscientes. É a aventura do conhecimento levando ao desencantamento total.

Tudo isto evidentemente está merecendo uma revisão, porque essa relação dialética entre Intelectual, conhecimento e espaço público, na afirmação de sua radicalidade, começa a dar um passo atrás e a negar o espaço público, a encurtá-lo. Do mesmo modo que as novas especializações criam universos restritos e circunscritos a novos detentores de novos saberes, a promessa de ampliação do espaço público e de interação com os intelectuais e com a busca do conhecimento começa a virar contra si mesma. As especializações começam a cercear o espaço da liberdade. Esse espaço da liberdade, da investigação passará a ser privilégio daqueles que detêm esses saberes; passará a ser privilégio de quem detém os códigos de acesso aos novos saberes.

Principalmente entre profissionais da educação, através das novas práticas e do controle do acesso aos novos saberes, constituíram-se muitos poderes. Para não falar dos macropoderes, no cotidiano da vida das universidades, das instituições de ensino, vemos, experimentamos, lutamos contra e às vezes somos cúmplices de novas formas de manipulação. É uma espécie de modernidade que já se revira sobre ela mesma, encur- 
tando o espaço púbico. E a maior perda vai se dar exatamente para a âncora fundamental desse espaço público: como o próprio nome diz, o público. É ele que começará a ser o novo excluído dos novos saberes, que são saberes feitos ou construídos para a liberdade. Já se nota, portanto, um primeiro recuo, uma espécie de encurtamento do espaço público, à medida que as especializações avançam, e avançam em seu sentido primordial, que é o de radicalizar o desencantamento e o de lançar a interrogação da razão sobre todos os aspectos da vida na Terra.

Nesse processo, vê-se ocorrer uma nova síntese, na qual caminham as especializações. Desse desencantamento, dessa constituição de práticas que são saberes e são também poderes, o conhecimento transforma-se em algo que passa a ser capaz de moldar a própria reprodução da sociedade, que passa a ser moldada cada vez mais pelo acúmulo e pela radicalização das especializações. É nesse momento, fatal na aventura do conhecimento, que o conhecimento vai se tornar uma mercadoria. Este é o seu "calcanhar de Aquiles". No momento em que as especializações passam a ser um diálogo circunscrito aos especialistas, no momento em que elas começam a moldar o próprio comportamento da Humanidade, o conhecimento deu um passo decisivo e transformou-se em mercadoria. $E$ uma mercadoria só se reproduz pela sua mimese, pela sua homogeneidade; a mercadoria recusa a diferença, recusa o diverso, recusa o plural; a mercadoria é univocidade.

Nesse caminho, o capital apossou-se do conhecimento. Não do conhecimento para a liberdade, mas do conhecimento como mercadoria, do conhecimento como molde de produção da sociedade, do conhecimento como controle do acesso aos saberes e poderes. Este é o passo decisivo, fundamental, o passo mais perigoso na aventura do conhecimento. Se quisermos nos servir de um pensador como Adorno, por exemplo, é aqui que vai se operar aquela espécie de "dialética negativa", sobre a qual Adorno tanto trabalhou. Se o caminho do progresso, se o caminho da modernidade havia sido lograr sínteses que ampliavam o espaço da liberdade, a nova síntese é uma síntese negativa, porque restringe os espaços da liberdade. Esse passo fundamental é dado exatamente quando o capital se apossa do conhecimento de uma forma bastante específica. Não como se apossa de qualquer mercadoria: apossa-se do conhecimento como indústria cultural. Aí a síntese negativa está operada. A indústria cultural vai borrar as diferenças entre Intelectuais, conhecimento e espaço público.

A indústria cultural transforma o conhecimento em informação, provocando a perda da radicalidade do conhecimento; tudo é transformado em informação. E a sociedade contemporânea está mergulhada numa intoxicação de informações sem paralelo. Parece que dispomos de todas as informações para operarmos a aventura do conhecimento. Mas esta intensa intoxicação provoca o contrário: o espaço da informação cresce enormemente e encurta-se de novo e com radicalidade o espaço público. Na verdade, a informação não cria novos interlocutores; cria um movimento mimético, que se repete incansavelmente - e podemos utilizar todos os exemplos citados na fala de abertura desta reunião. Estamos há um mês intoxicados pelo excesso de informações sobre o que se passou em Nova York e sobre o que vai se passar, e o que já está se passando no Afeganistão. Não aumentou um milímetro nossa capacidade de conhecer o que havia se passado em Nova York e o que está se passando no Afeganistão. As horas gastas diante da televisão e na leitura de todos os jornais de todo o mundo não acrescentam um milímetro ao nosso conhecimento sobre os processos que detonam a barbárie. O que existe em lugar disso é uma redução, uma operação reducionista do complexo ao simples. Se o movimento da razão foi desvendar cada vez mais a natureza do complexo, daquilo que produz a sociedade, de perscrutar sua inexplicável complexidade, a intoxicação de informações vai no sentido contrário. Hoje sabemos apenas, - ou pensamos saber e na verdade nada sabemos -, que o que se passou em Nova York e o que se está passando no Afeganistão deriva simplesmente de uma luta entre o Bem e o Mal. Para os crentes, isto já era sabido desde Adão e Eva; e para os não-crentes, restou o enrome enigma. A vasta complexidade da sociedade norte-americana, uma das 
mais complexas do mundo, e a vasta complexidade das sociedades árabes e muçulmanas foram reduzidas à velha dualidade e polaridade do Bem contra o Mal. Há atributos das raças, atributos das religiões, e continuamos a ouvir, fascinados pela imagem, informações que não nos acrescentam absolutamente nada.

Esta é a indústria cultural como movimento mimético que repete, repete, repete e não aprofunda em nada o conhecimento. Esse movimento do real nos escapa sob toneladas de informações. No momento em que a transformação do conhecimento, - na verdade seu simulacro -, se reduz à informação, o que acontece com o intelectual? E, na outra ponta, o que acontece com o espaço público? O intelectual deixou de ser intelectual; é um comunicador. Mesmo no caso dos Estados Unidos da América, os grandes intelectuais norte-americanos, as vozes da razão, aqueles que se ergueram contra a guerra no Vietnã, não são quase ouvidos. E já há, nos Estados Unidos, não uma velada, mas uma aberta censura ao pensamento radical e ao pensamento que se diferencia. Os comunicadores, digamos, se pudéssemos fazer uma relação remota, são os novos oráculos. Isso ocorre em todas as áreas do conhecimento e da aventura humana. Os "grandes" da literatura hoje não são os Joyces subversivos, mas são os Umberto Eco, que fabricam romances como se fabrica lingüiça. Para fazer um poema, "tome um pouco de azul, se a tarde é clara", dizia meu poeta preferido do Recife; "tome os condimentos necessários, dose-os convenientemente e você obterá um romance". E a aventura de subversão lingüística, a criação de novas formas foi perdida. Cito Umberto Eco propositadamente, até porque é, antes de tudo, um semiótico. Ele descobriu as engrenagens de como transformar conhecimento em informação, em comunicação. Eu o cito porque é um autor fascinante! Certamente muitos estarão lendo Baudolino, sua última façanha, mas evidentemente entre Baudolino e Ulisses a diferença é toda a Odisséia.

Há quem não concorde com essa divisão entre a grande literatura e a do gênero Paulo Coelho. Aqui não é o espaço para tratar dessa questão, mas, definitivamente, minha posição é que essa diferença é fundamental.
Voltando ao nosso tema, quem perde com a redução do espaço público é a polis; é exatamente a política que perde, pois a polis é o lugar da interlocução. Não há interlocução na comunicação. Ela é completamente falsa, mesmo na chamada "televisão interativa": de um lado estão as imagens da Rede Globo e do outro lado nós, que podemos reagir, através de respostas a perguntas cretinas. No Admirável Mundo Novo de amanhã, poderemos dispor de videofones, através e por meio dos quais entraremos em comunicação direta com as emissoras da Rede Globo. Teremos chegado então a quebrar o monopólio? Nem de longe. Continuará a ser um simulacro, porque informação não é conhecimento. E travaremos desta vez não um diálogo de surdos, mas um diálogo com gente que tem muita capacidade de ouvir e pouca capacidade de pensar. É a polis que perde em primeiro lugar, e quem perde na polis são exatamente aqueles que, no processo anterior, já haviam sido excluídos do conhecimento pela dinâmica das especializações e que agora são engolfados pela indústria cultural, mas não pertencem a ela e nem ao seu campo; são apenas utilizados como receptores passivos desta intoxicação de informações.

Este é um tema que deveria preocupar muito a todos nós, que militamos nas ciências do homem, nas ciências sociais, na educação, porque estas áreas são as mais atingidas pela massificação da indústria cultural. Nossas investigações passam a ser medidas pelo metro da produtividade, e isso já está em todos os critérios de julgamento das pesquisas. Ao nos submetermos às várias agências para recebimento de recursos, temos que responder a questões sobre a produtividade de nossas pesquisas. É o mesmo metro que mede a produção de uma mercadoria. Há pouca diferença, ainda, entre elas. Tratemos de preservar essa diferença, porque elas estão sumindo rapidamente na forma até dos questionários que são inteiramente padronizados. A mim, que acorro muitas vezes aos guichês dessas instituições, me perguntam: Qual é o público-alvo da sua pesquisa? Se responder sinceramente, me serão cortados os recursos. Se responder que não tenho um público-alvo; que o público não é um alvo; que o público é o meu outro, com quem dialogo, através da 
minha posição de intelectual, certamente eles terão razão para cortar-me os recursos. Mas não estou ainda suficientemente louco para ver cortados os recursos para pesquisa.

Há, portanto, nesse processo, contraditoriamente, um encolhimento do conhecimento substituído pela informação. A relação Intelectuais, conhecimento $e$ espaço público entra em crise. O espaço público não é apenas publicização; tem sido usado recorrentemente, até com boas intenções, como critério da publicização: publicizemos que aí estará cumprido, não só o ritual, mas a essência do processo do público. Isso pode ser um enorme equívoco, porque o público não é apenas publicização, o público é o outro pelo qual e somente através do qual se reproduz e se produz conhecimento. O público não é publicidade, não pode ser confundido com ela. A publicidade é um requisito do público, mas o público não se esgota nela. Vai mais além, transcende o espaço da publicidade para requerer o outro como elemento constitutivo, como o momento da sua produção e reprodução. É precisamente isto que a informação não dá. A informação não requer o outro, mesmo que, através das televisões ditas interativas, alguém nos pergunte nossa opinião sobre a seleção do Felipão; isto não nos dá a possibilidade de entrar em interlocução com o Felipão.

Nesse processo, não há necessidade do outro para produzir o discurso daquele que emite o discurso. Esse encolhimento do espaço público é o outro lado da intensa pressão e tendência à privatização da vida, um fenômeno que dirige hoje todos os nossos esforços; dirige o nosso cotidiano e está presente em todos os acontecimentos. A tendência à privatização da vida confunde-se com tendência de liquidar, diluir e dissolver o espaço público. Ela se mostra de forma taxativa e quase irrecorrível, praticamente em todas as arenas de nossas tarefas cotidianas. Esse movimento de privatização da vida, para o qual todos corremos desesperadamente, transforma-se numa espécie de subjetividade antipública. Em decorrência, produz um estranhamento, produz um medo do outro - este medo que percorre toda a sociedade contemporânea. Estamos aqui juntos, nesta assembléia, nesta polis em miniatu- ra; ao voltarmos para nossas casas nos recolheremos aos nossos condomínios privados, cercados de guaritas, monitorados por câmaras de vídeo, presentes hoje nos espaços de circulação e amanhã no interior de nossas casas. A privatização da vida provoca o medo, provoca essa subjetivação antipública em que nos colocamos como seres privados, como se houvesse a possibilidade de existirem seres privados sem o outro.

Nesse momento, essa tendência percorre toda a sociedade contemporânea. E em sociedades tão desiguais como a nossa, a privatização da vida é uma das piores marcas e reforços da desigualdade. A desigualdade não consiste tanto nas diferenças de poder, - embora como um velho materialista acredite que ela consiste sim nas diferenças de poder -; ela consiste muito mais na espécie de intranscendentalidade do outro, nesta barreira entre os próprios indivíduos, no medo que toma conta de cada um de nós, ao ponto de não ousarmos mais sair nas ruas, em nossas cidades. Essa subjetivação antipública é recorrentemente remontada e reconstruída; por isso é uma grande indústria cultural - hoje, de forma mais sofisticada, chamada mídia. Ela reforça todo tempo o estigma do público, levandonos a pensar e a nos comportar como se pudéssemos esgotar a nossa sede do outro e a nossa multiplicidade vivendo dentro de casa.

Essa tendência leva-nos a nos recolher do espaço público para o espaço privado. Toda a tecnologia é uma tecnologia voltada para a privatização da vida. $\mathrm{O}$ computador, que já é hoje o nosso companheiro cotidiano e que já serve até para fazer amor virtual, é este e não-outro que nos isola, por mais que trabalhemos "em rede". Quem pensa, como Castells, que com isso se está desfazendo o isolamento, incorre em um profundo equívoco. Redes não substituem a convivência! Redes não substituem o estar junto!

Essa tendência apresenta-se como síntese negativa. E a síntese negativa trabalha como uma espiral descendente: se no auge da modernidade, se no seu impulso original a síntese era uma espécie de espiral ascendente que resolvia um problema para colocar outro num patamar superior, apanhando as contradições anteriores e resolvendo-as no maior grau de li- 
berdade, a nova síntese negativa é reducionista. Novamente, o exemplo que temos mais à mão é a tragédia americana, que coloca do outro lado árabes, muçulmanos e agora afegãos. Houve a tragédia; a síntese negativa não se resolveu na busca da ampliação dos espaços de interlocução da sociedade norte-americana, para que ela possa viver o luto da experiência mortífera. A síntese negativa resolve-se reduzindo o espaço da liberdade, das pessoas, dos indivíduos, dos homens e mulheres e, do outro lado, ampliando o espaço do capital. A nova legislação aprovada pelos Estados Unidos restringe fortemente a liberdade individual. Ao mesmo tempo, as companhias de aviação fazem o primeiro pedido da crise: serem socorridas pelo Tesouro Americano. A nova síntese, portanto, não significa sequer ampliação simultânea de duas liberdades contraditórias; ela se resolve na negação total na liberdade dos indivíduos, enquanto amplia do outro lado o espaço do capital.

Este é um exemplo da anulação da relação Intelectual, conhecimento e espaço público. Exemplo dramático porque ocorre na sociedade que levou mais longe do que qualquer outra os desígnios e promessas do liberalismo, sobretudo do liberalismo político. Não foram atingidas somente as torres do World Trade Center; o que foi atingido fundamente foi o princípio liberal, este princípio da liberdade. E a síntese negativa volta a manifestar-se; quando aparentemente, pela quantidade de informações e até pelo décor da tragédia, tudo aponta para uma revivescência e uma ampliação do espaço público, a resolução é pela sua negação. Por que isso é importante para quem trabalha exatamente com o conhecimento? Para quem trabalha com a educação? E para quem trabalha no campo das ciências humanas e das ciências sociais? Porque não se pode mais sequer instaurar uma linguagem científica, no campo das ciências humanas. A síntese negativa nega também a possibilidade da linguagem científica, principalmente no campo das ciências humanas. Todos nós estamos acometidos de uma invasão de termos que vem de outros campos científicos, o que é muito antigo na história do conhecimento. A própria sociologia tomou muitos termos da biologia para po- der estruturar o seu próprio campo de interrogações. O mais grave não é a tomada por empréstimo de termos usados hoje correntemente; é tomarmos o modelo da Natureza para pensar os problemas do Homem. O mais grave é a sociobiologia pensar a sociedade como um organismo biológico; o que estava na gênese da sociologia, que a ajudou a nascer e a se estruturar, aparece hoje como um momento de sua negação. O mais grave, portanto, é que isso anula a possibilidade de uma linguagem e da pesquisa científica e nos encaminha irremediavelmente para um movimento de repetição, para um movimento minimalista.

Este é o risco maior que temos de enfrentar neste momento. Devemos assumir essa batalha como conseqüência do campo que escolhemos para nossas atividades profissionais, mas sobretudo do campo que escolhemos para ampliação do espaço da liberdade. Essa é a tarefa que as ciências humanas, as ciências sociais e a educação já têm há muito tempo, mas dramatizada agora pelos recentes acontecimentos. Dramática também no Brasil, onde a relação entre Intelectuais, conhecimento e espaço público é bastante antiga. $\mathrm{Na}$ fala de abertura dessa assembléia e na saudação a mim feita, foram citados alguns clássicos do pensamento social brasileiro, aqueles que dedicaram suas obras, seus talentos a tentar interrogar a formação da sociedade brasileira. A maior parte desses intelectuais foi varrida de nossas bibliografias. Nos cursos oferecidos hoje pela universidade, em que lugar está Anísio Teixeira? Onde se ensina, nas ciências sociais, o pensamento de Florestan Fernandes? Esses intelectuais não estão sendo varridos, na velha metáfora, "para baixo do tapete" ; estão sendo expulsos do pensamento universitário. Não apenas porque autores estrangeiros de maior prestígio ou de maior novidade estejam em moda - este é sempre um fenômeno passageiro -, mas sobretudo porque essa espécie de sociobiologização das ciências sociais e das ciências humanas impede uma nova interlocução com os "velhos" intelectuais, com nossos clássicos.

Este é o risco maior! A este risco a sociedade brasileira não pode responder como se não lhe interessasse. Diriam os cínicos: este pode ser um problema para 
acadêmicos, pode ser um problema para pensadores da educação, mas não é um problema para grande parte da população que necessita de feijão com arroz, de um prato de comida todo dia. Este tipo de pensamento ocorre até nos mais bem intencionados. Eu já ouvi muita gente de esquerda dizer que a primeira coisa a fazer no Brasil seria uma reforma que desse ao menos um prato de comida a cada dia, a cada um dos brasileiros. Pode haver equívoco maior, mas eu não o conheço. Nesta sociedade, tão marcadamente desigual, a eliminação do campo de interlocução será fatal para a polis; será fatal sobretudo para os dominados, sobretudo para aqueles que carregam em si, em sua existência todos os estigmas da formação dessa sociedade tão desigual. É a eles que se endereça, na verdade, a privatização da vida. São eles o alvo preferencial dessa privatização e desse encolhimento do espaço público. De novo: porque é na polis que se produz a política capaz de reverter essa situação.

Quem pensar que é no conflito privado, no conflito da fábrica, no conflito do escritório que resolvemos a questão da liberdade e da igualdade, não sabe da missa o terço. Não se resolve o conflito no espaço privado, mesmo porque, como o atentado em Nova York mostrou, o espaço privado é insuficiente mesmo para as atividade privadas. Temos à mão outro exemplo, que nos vem dessa vez da Suíça, a terra onde parece que a promessa bíblica tinha se cumprido, porque é lá que corre o mel, o leite, o chocolate e o dinheiro. Mas na Suíça bíblica também chegou a hora da verdade: sua companhia aérea mais importante declarou-se falida e foi socorrida pelo governo. Mesmo os conflitos privados não podem se processar fora da arena pública; ela é a única condição capaz de contemplar os próprios interesses privados. Portanto, não caiamos no equívoco de esquecer a política da educação como prioritária. Para a própria polis, esta é a prioridade fundamental, a prioridade número um, a que temos que nos dedicar e dedicar todas nossas forças para orientar a política no Brasil, um país cuja desigualdade não precisa ser reforçada nem exagerada.

Podemos tomar o simulacro da comunicação e perguntar: onde estão os intelectuais? Onde está a pro- dução de conhecimento? Parece um paradoxo, dado que evidentemente os intelectuais escrevem nos jornais e supõe-se que são, de alguma maneira, lidos e ouvidos. O que pareceria, portanto, que eu estou falando de algo completamente irreal. Na verdade, a capacidade de interlocução está grandemente reduzida. Ela não foi anulada completamente, mas encontra-se quase que totalmente escanteada do espaço público. Basta tomarmos qualquer um de nossos jornais, desde os mais paradigmáticos, começando pela Folha de $S$. Paulo, que é uma espécie de umbigo do próprio narcisismo. Fazendo as contas pelo método mais simples, onde estão as matérias, e qual é a quantidade de espaço dedicado a cada uma delas, assinadas pelas expressões maiores da intelectualidade brasileira? Na coluna diária da Folha de S. Paulo, publicada na parte à direita da segunda página, encontraremos, - salvo Roberto Mangabeira Hunger e tirando Dom Luciano Mendes de Almeida, que nos últimos tempos tem-se dedicado quase apenas à piedade -, figuras eminentes do empresariado e da direita brasileira. Sem erro! A Folha faz uma espécie de compensação: bota uma coisa ali naquela coluna e do outro lado o Clóvis Rossi que dá, de vez em quando, uma de céptico, frio, distante. Sob qualquer critério, ver-se-á que, neste simulacro no qual a informação se transformou, há uma predominância daquilo que se caracterizou nesta época como uma espécie de pensamento único. Isto não cria nenhuma interlocução. Sem interlocução o espaço público que parece ampliar-se, a rigor se encolhe. Encolhe-se por não incluir novos interlocutores, por não tomar o pressuposto de que o outro é um ser dotado de razão.

A greve das universidades federais é um exemplo atual e importante. Toda a argumentação é de que os professores e funcionários das universidades em greve são destituídos de razão. Eles não são capazes de perceber as razões do orçamento da União, pelas quais suas reivindicações não podem ser atendidas. Todo o tempo é jogado sobre a opinião pública essa falsificação do público: a idéia de que petições e reivindicações são algo que atentam contra os fundamentos da política econômica e contra os fundamentos da Repú- 
blica. Em outras palavras: professores, funcionários e alunos são transformados em inimigos públicos. Este processo recorrente de negação é o encolhimento do espaço público em lugar de sua ampliação.

Por essa subjetividade antipública, que se vai construindo à medida que o conhecimento transformase em informação e que a informação torna-se um simulacro do conhecimento, em outras palavras, nessa indústria cultural, ou como Fredric Jameson o chamou, nesse capitalismo cultural, os intelectuais são descartáveis. Trata-se agora, como qualquer mercadoria, da descartabilidade permanente; por isso a idéia do público encontra tão pouca acolhida. É preciso perguntar qual a corrente profunda que alimenta esse processo; sem uma resposta adequada, não seremos capazes de deslindar esse enigma e nem capazes de armar nossas universidade, nossas investigações, com as questões mais fundamentais. Não é epidérmico esse sentimento; não se trata apenas da propaganda raivosa. Tratase de um processo que percorre fundamente a própria formação da sociedade. Uma enorme contradição, posto que todas as outras formas de atendimento são discriminatórias. A forma do público é a única não discriminatória, o que não quer dizer muita coisa porque o Diabo é o Diabo, não porque é velho, porque ele é o Diabo. Não quer dizer que o público atenda a todas as situações; quer dizer sim que é a única forma pela qual as novas e as velhas reivindicações podem algum dia chegar a ser atendidas. Todas as outras formas são discriminatórias. Como provam os exemplos dos Estados Unidos da América do Norte e da Suíça, mesmo ali o mercado não é capaz, pois reintroduz critérios de discriminação, que são critérios de classe. Esta é a questão que está em jogo. E o desafio é enorme, em especial para os educadores: desfazer essa tendência antipública formada nos subterrâneos, formada no rio profundo que percorre a sociedade. É um trabalho que só nós mesmos, dedicados à educação, podemos fazer. E podemos fazê-lo porque somos insanos! 